\title{
DÜBLIN
}

Technological University Dublin

ARROW@TU Dublin

Articles

School of Physics \& Clinical \& Optometric

Science

2020

\section{Smartphone Use as a Possible Risk Factor for Myopia}

\author{
Saoirse McCrann \\ Technological University Dublin, Ireland \\ James Loughman \\ Technological University Dublin, james.loughman@tudublin.ie \\ John Butler \\ Technological University Dublin, john.s.butler@tudublin.ie
}

See next page for additional authors

Follow this and additional works at: https://arrow.tudublin.ie/scschphyart

Part of the Medicine and Health Sciences Commons

\section{Recommended Citation \\ McCrann S. (2020)Smartphone use as a possible risk factor for myopia. Clin Exp Optom. 2020. \\ DOI:10.1111/cxo.13092}

This Article is brought to you for free and open access by the School of Physics \& Clinical \& Optometric Science at ARROW@TU Dublin. It has been accepted for inclusion in Articles by an authorized administrator of ARROW@TU

Dublin. For more information, please contact arrow.admin@tudublin.ie, aisling.coyne@tudublin.ie, gerard.connolly@tudublin.ie.

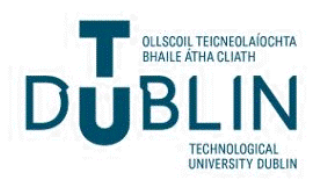




\section{Authors}

Saoirse McCrann, James Loughman, John Butler, Nabin Paudel, and lan Flitcroft 


\section{CLINICAL AND EXPERIMENTAL OPTOMETRY

\section{Smartphone usage as a possible risk factor for myopia}

\begin{tabular}{|c|c|}
\hline Journal: & Clinical and Experimental Optometry \\
\hline Manuscript ID & CEOptom-20-046-OP.R3 \\
\hline Manuscript Type: & Original Research Paper \\
\hline $\begin{array}{l}\text { Date Submitted by the } \\
\text { Author: }\end{array}$ & $n / a$ \\
\hline Complete List of Authors: & $\begin{array}{l}\text { McCrann, Saoirse; Technological University Dublin, Centre for Eye } \\
\text { Research Ireland, School of Physics, Clinical and Optometric Sciences } \\
\text { Loughman, James; Technological University Dublin, Centre for Eye } \\
\text { Research Ireland, School of Physics, Clinical and Optometric Sciences; } \\
\text { African Vision Research Institute } \\
\text { Butler, John; Technological University Dublin, School of Mathematical } \\
\text { Sciences } \\
\text { Paudel, Nabin; Technological University Dublin, Centre for Eye Research } \\
\text { Ireland, School of Physics, Clinical and Optometric Sciences } \\
\text { Flitcroft, Ian; Technological University Dublin, Centre for Eye Research } \\
\text { Ireland, School of Physics, Clinical and Optometric Sciences; Children's } \\
\text { University Hospital }\end{array}$ \\
\hline Keywords: & $\begin{array}{l}\text { lifestyle, myopia, myopia prevention, risk factors, smartphones, } \\
\text { environment, technology }\end{array}$ \\
\hline Abstract: & $\begin{array}{l}\text { Clinical Relevance } \\
\text { This study demonstrates an association between myopia and smartphone } \\
\text { data usage. Youths now spend more time participating in near tasks as a } \\
\text { result of smartphone usage. This poses an additional risk factor for } \\
\text { myopia development/progression and is an important research question } \\
\text { in relation to potential myopia management strategies. } \\
\text { Background } \\
\text { Children are now exposed to another possible environmental risk factor } \\
\text { for myopia-smartphones. This study investigates the amount of time } \\
\text { students spend on their smartphones and their pattern of smartphone } \\
\text { usage from a myopia perspective. } \\
\text { Methods } \\
\text { Primary, secondary and third-level students completed a questionnaire } \\
\text { exploring patterns of smartphone usage and assessing their attitudes } \\
\text { towards potential myopia risk factors. Device-recorded data usage over } \\
\text { an extended period was quantified as our primary and objective indicator } \\
\text { of phone use. Average daily time spent using a smartphone was also } \\
\text { quantified by self-reported estimate. Refractive status was verified by an } \\
\text { optometrist. } \\
\text { Results } \\
\text { Smartphone ownership among the } 418 \text { students invited to participate } \\
\text { was over } 99 \% \text {. Average daily smartphone data and time usage was }\end{array}$ \\
\hline
\end{tabular}


$800.37(+/-1299.88) M B$ and $265.16(+/-168.02)$ minutes respectively. Myopic students used almost double the amount of smartphone data at $1130.71(+/-1748.14) M B$ per day compared to non-myopes at 613.63 $(+/-902.15) M B(P=0.001)$. Smartphone time usage was not significantly different ( $P=0.09,12 \%$ higher among myopes). Multinomial logistic regression revealed that myopic refractive error was statistically significantly associated with increasing daily smartphone data usage (odds ratio $1.08,95 \%$ CI1.03 to 1.14) as well as increasing age (odds ratio $1.09,95 \%$ CI1.02 to 1.17 ) and number of myopic parents (odds ratio $1.55,95 \% \mathrm{CI} 1.06$ to 2.3 ). $73 \%$ of students believed that digital technology may adversely affect their eyes.

Conclusion

This study demonstrates an association between myopia and smartphone data usage. Given the serious nature of ocular health risks associated with myopia, our findings indicate this relationship merits more detailed investigation.

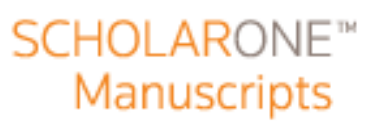




\title{
RESEARCH \\ Manuscript ID CEOptom-20-046-OP entitled "Smartphone usage as a possible risk factor for myopia"
}

\author{
Authors \\ Saoirse, SMC, McCrann, PhD BSc Optometry* \\ James, JL, Loughman, PhD BSc Optometry*ף \\ John S, JSB, Butler, PhD MSc BA Mathematics $\dagger$ \\ Nabin, NP, Paudel, PhD B Optometry* \\ Daniel Ian, IF, Flitcroft, D.Phil MB BS MA FRCOphth*§
}

\begin{abstract}
Author affiliations
* Centre for Eye Research Ireland, School of Physics, Clinical and Optometric

Sciences, Technological University Dublin, Ireland.

$\uparrow$ School of Mathematical Sciences, Technological University Dublin, Ireland.

$\S$ Children's University Hospital, Dublin, Ireland.

I African Vision Research Institute, University of KwaZulu Natal, Durban, South Africa.
\end{abstract}

\section{Running head}

Smartphones as a possible risk factor for myopia

Keywords lifestyle, myopia, myopia prevention, risk factors, smartphones 


\title{
Clinical Relevance
}

This study demonstrates an association between myopia and smartphone data usage. Youths now spend more time participating in near tasks as a result of smartphone usage. This poses an additional risk factor for myopia development/progression and is an important research question in relation to potential myopia management strategies.

\section{Background}

Children are now exposed to another possible environmental risk factor for myopiasmartphones. This study investigates the amount of time students spend on their smartphones and their pattern of smartphone usage from a myopia perspective.

\begin{abstract}
Methods
Primary, secondary and third-level students completed a questionnaire exploring patterns of smartphone usage and assessing their attitudes towards potential myopia risk factors. Device-recorded data usage over an extended period was quantified as our primary and objective indicator of phone use. Average daily time spent using a smartphone was also quantified by self-reported estimate. Refractive status was verified by an optometrist.
\end{abstract}

\section{Results}

Smartphone ownership among the 418 students invited to participate was over $99 \%$. Average daily smartphone data and time usage was 800.37 (+/-1299.88)MB and 265.16 $(+/-168.02)$ minutes respectively. Myopic students used almost double the amount of smartphone data at $1130.71(+/-1748.14) \mathrm{MB}$ per day compared to non-myopes at $613.63(+/-902.15) \mathrm{MB}(\mathrm{P}=0.001)$. Smartphone time usage was not significantly different ( $\mathrm{P}=0.09,12 \%$ higher among myopes). Multinomial logistic regression revealed that myopic refractive error was statistically significantly associated with increasing daily smartphone data usage (odds ratio $1.08,95 \%$ CI 1.03 to 1.14 ) as well as increasing age (odds ratio $1.09,95 \%$ CI 1.02 to 1.17 ) and number of myopic parents (odds ratio $1.55,95 \%$ CI 1.06 to 2.3 ). $73 \%$ of students believed that digital technology may 
adversely affect their eyes.

\section{Conclusion}

This study demonstrates an association between myopia and smartphone data usage.

Given the serious nature of the ocular health risks associated with myopia, our findings indicate that this relationship merits more detailed investigation. 
Myopia is predicted to affect almost 5 billion people worldwide by $2050,{ }^{1}$ and is a global public health concern with significant social, educational, and economic consequences. ${ }^{2}$ The onset of myopia has also shifted to a younger age,${ }^{3}$ which is a concern, as younger children exhibit more rapid myopia progression ${ }^{4}$ and are more likely to reach higher levels of myopia. This can substantially increase the risk of developing sight threatening conditions including myopic maculopathy, glaucoma, cataract and retinal detachment in later life. ${ }^{5}$

The aetiology of myopia is multifactorial, involving interplay between genetic environmental and behavioural factors, with decreased time outdoors, ${ }^{6}$ urbanisation, ${ }^{7}$ disturbed/delayed sleep, ${ }^{8,9}$ increased time spent in education ${ }^{10}$ and time spent reading continuously or in long periods of close work all cited as possible influences. ${ }^{11}$

Children and young adults are now exposed to another possible environmental risk factor for myopia - digital devices. ${ }^{12}$ Smartphones, iPads, tablets and computers are used at a very early age in both home and school environments. ${ }^{13}$ Children are the fastest growing population of smartphone users, ${ }^{14}$ with $95 \%$ of American teenagers reporting ownership of or access to a smartphone in 2018. ${ }^{15}$ Smartphones are now the most used device for internet access on a daily basis by $9-16$ year olds in Ireland, ${ }^{16}$ while $85 \%$ of young people in the UK (aged 12-15) use a smartphone daily. ${ }^{17}$

Several studies have identified computer usage as a risk factor for myopia. ${ }^{18-23}$ One study in particular, found myopia was associated with a closer computer screen working distance..$^{20}$ The working distance adopted by smartphone users is typically even closer than for computer screens. ${ }^{24}$ It is conceivable, therefore, that increased and continuous exposure to a smartphone screen might represent a plausible risk factor for the development or progression of myopia, especially in younger age groups. There is, however, a scarcity of published literature investigating the relationship between smartphone use and myopia. Recent studies that have addressed the ocular impact of smartphone use have focussed on self-reported estimates of time spent on a 
smartphone, ${ }^{25-28}$ even though self-reported smartphone assessments have been shown to perform poorly when attempting to predict objective smartphone behaviours. ${ }^{29}$

This study was designed to investigate self-reported and device-tracked smartphone usage among children and young adults to determine whether any association exists with refractive status. Furthermore, the attitudes of students to mobile phones and digital technology as a risk factor for myopia were also explored.

\section{METHODS}

Students across the spectrum of primary school (kindergarten to grade 6), secondary school (corresponding to grades 7-12) and tertiary (or university level) education settings were invited to participate in the study between January and March 2018. This was facilitated by an 'invitation to participate' email request sent to University staff via University administrators and to schools in the Republic of Ireland by the study investigator directly. The study investigator visited participating classrooms and potential participants were provided with a questionnaire. The study investigator explained the instructions on the questionnaire carefully with each class, and any questions were answered. For participants aged 16 and over, a consent form was signed and the questionnaires were completed instantly and collected by the study investigator. Students under the age of 16 and any subject over 16 who did not have their phone present in the classroom completed the questionnaire for homework along with the parental consent form (where applicable), and returned it to their teacher the following day. Completed forms were collected one week after distribution. Schools were contacted the day before the study investigator's return, to remind students to return their questionnaires if they had not done so. All students present on the day of the initial investigator visit agreed to participate in the study.

As the study was performed in a classroom rather than a clinical setting, a simple optometrist-led method was used to separate myopes from non-myopes. Prior to the study investigator visit participants (or parents) were requested to bring a copy or photograph of their glasses or contact lens prescription to school, which was 
documented by the investigator. The investigator, a qualified optometrist, confirmed refractive status (including for those without a written prescription) by questioning student's use of their spectacle/contact lens prescription, their unaided signs and symptoms and by examining the students' spectacles to determine if lenses were convex (magnifying and hence hyperopic) or concave (minifying and hence myopic).

An initial draft questionnaire was constructed and subsequently analysed by an external reviewer with expertise in questionnaire design. The questionnaire was pilot tested on five people (two primary school students, two secondary school students and one university student), after which it was edited to remove leading or confusing questions. For Android users, smartphone data usage was queried by going into Settings $>$ Data Usage $>$ Mobile Data Usage as well as Settings $>$ Data Usage $>$ WI-FI Data Usage. For iPhone users, smartphone data usage was found via Settings $>$ Mobile Data $>$ Data Usage in Current Period, as well as Settings $>$ Mobile Data > WI-FI Data Usage. Participants were asked to record the time period for data usage based on their current usage period (for Android users) or date of last reset (for iPhone users). These values are available within the phone settings and indicates the date from which the phone has been logging cellular data usage.

Average daily data usage was calculated by dividing the number of days from the last data reset by the amount of data used. Students were also asked to record the three applications (apps) that used the most data. Smartphone usage was also assessed by self-report. Participants were asked to estimate how much time they spend on average per day using their phone, the longest period of time spent on their phone at any one period in a week and how long they spend looking at their phone after going to bed. Nine tick box questions were used to capture participant demographics, record participant and self-reported parental myopia status, explore patterns of smartphone use (e.g. whether used to read or watch TV programs, use for social media, internet etc.), quantify how often the phone was used after going to bed and to determine if participants thought the use of a phone screen impacted their eyes. An open-ended question probed participants' thoughts on the potential impact of the screen on their 
eyes. Parents were asked to assist in answering the questionnaire for participants under 16 years old.

Questionnaires were anonymous; participants were assured that all individual results would be kept strictly confidential. Participation in the study was voluntary. The study was approved by the Research Ethics Committee at Technological University Dublin. All data was collected between January and March 2018. The data collected was analysed on the statistical package for social sciences (IBM SPSS Statistics for Windows, Version 22.0 Armonk, NY: IBM Corp.) and R version 3.2.2.in RStudio (RStudio Team,2015. RStudio: Integrated Development for R. RStudio, Inc., Boston, MA URL http://www.rstudio.com/). The Kolmogorov-Smirnov Test for normality determined the smartphone usage data was not normally distributed. A boxcox transformation was therefore used to normalise smartphone data usage and time usage to facilitate parametric analysis. Non- parametric tests were used and the median and confidence intervals were reported where appropriate. The results were analysed using descriptive statistics and inferential statistics including Spearman's Rank-Order Correlation, chi-square tests of independence, Kruskal-Wallis and Mann Whitney U tests. A statistical significance level of $\mathrm{P}<0.05$ was adopted throughout the analysis.

\section{RESULTS}

\section{Demographics}

Three of the $418(<1 \%)$ students initially invited to participate in the study did not own a smartphone (but used their parent's smartphone) and were excluded as their personal data usage could not be identified. 402 participants (96\%) aged between 10-33 years provided informed consent and completed the questionnaire $(54 \%, 216 / 402$ female; 45\%, 181/397 male; 1\%, 5/402 not stated). The mean age was 16.77 (standard deviation [or $+/-] 4.4)$ years and 34\% (138/402) of participants wore glasses/contact lenses for myopia. The mean age at which myopic participants were first prescribed glasses was 11 years (range 3,19 ). There was some minor loss of data on specific questions due to incomplete responses or inability to confirm refractive status 
(spectacles or spectacle/contact lens Rx not provided by 6 participants). A detailed description of the recruitment setting, data capture and refractive status confirmation of all participants is provided in Figure 1, while participant demographics, behaviours and beliefs according to refractive status are provided in Table 1.

\section{Smartphone Usage}

Students used an average of $873 \mathrm{MB}(+/-1038)$ of data per day and spent an average of 4 hours and $32(+/-169)$ minutes per day on their phone. The longest period of time students reported spending on their phone at any one period in a week was an average of 3 hours $28(+/-188)$ minutes. The mean period of time since smartphone data was last reset was 215 (+/-320) days. Data usage among myopic students was statistically significantly higher $(84 \%$ higher, $\mathrm{P}=0.001)$ than non-myopes - see Table 1 . Selfreported smartphone time usage was not statistically significantly $(\mathrm{P}=0.09)$ different between myopes and non-myopes (12\% higher self-reported use among myopes)- see Table 1.

Spearman's correlation revealed daily data usage $(\mathrm{r}=0.14, \mathrm{df}=311, \mathrm{P}=0.01)$ and daily time spent on a smartphone $(\mathrm{r}=0.04, \mathrm{df}=311, \mathrm{P}=0.41)$ was positively correlated with age. Simple linear regression analysis was used to test the relationship between boxcox normalised daily data usage and daily time spent on phone. The results of the regression indicated $3 \%$ of the variance could be explained by the model (daily data usage versus daily time $)\left(\mathrm{R}^{2}=.0327, \mathrm{~F}(1,302)=10.2, \mathrm{P}<0.002\right)$.

The variation of data usage and time spent on a phone as a function of age/educational level is shown in Figure 2. The distribution of smartphone usage, particularly data usage, was positively skewed in both refractive groups. Non-parametric analysis (Mann-Whitney U test) for each educational level showed a significant difference in daily data usage between myopic and non-myopic university students $(\mathrm{P}=0.018)$ and a significant difference in daily time on phone between myopic and non-myopic primary school students $(\mathrm{P}=0.015)$. Other comparisons were not significant. Log transformation of the usage data still resulted in a small amount of negative skew, as shown in the box- 
and-whisker plots in Figure 2. Subsequent parametric analysis on smartphone data usage was therefore performed following normalisation using a boxcox transformation.

$84 \%$ (342/406) of students reported using their phone in bed. Spearman's correlation revealed age and time spent on a phone in bed were inversely correlated $(\rho(323)=$ $0.25, \mathrm{P}=0.0001$ ), with younger participants spending more time on a smartphone in bed compared to older students.

For the majority of participants $(72 \% ; 301 / 418)$, the main purpose of their smartphone was to use social media applications (apps) that involve screen interaction. Snapchat, Instagram and Facebook were the most used apps across all age groups and refractive error profiles. Spotify, podcasts and music applications that require less visual interaction by users were the most used applications by only four participants in the study.

\section{Parent myopia status}

Myopic participants with one $(\mathrm{P}=0.01)$ and two $(\mathrm{P}=0.04)$ myopic parents were first prescribed glasses for myopia at a younger age compared to myopic participants with no parental history of myopia.

\section{Gender}

A Chi-squared test of independence revealed myopia status was not statistically significantly dependent on gender $\chi^{2}(1)=3.5712, \mathrm{P}=0.058$.

\section{Beliefs regarding digital technology and eye health}

Overall 73\% (296/406) of students believed that digital technology may adversely affect their eyes, which was inversely correlated with age $(\rho(402)=-0.15, \mathrm{P}=0.003)$. This belief was expressed statistically significantly more often by myopes $(84 \% ; 112 / 134)$ than non-myopes $(68 \% ; 175 / 259)(\mathrm{P}=0.001)$. Participants regarded screen usage as a cause of various symptoms including eye strain $(29 \% ; 111 / 386)$, dry eyes $(67 \%$; $28 / 386)$, headaches $(5 \% ; 18 / 385)$, and difficulty reading $(2 \% ; 9 / 383)$. A similar 
proportion of myopes $(31 \%, 39 / 127)$ and non-myopes $(25 \%, 61 / 246)$ expressed an opinion that a link existed between myopia and increased time spent looking at a screen $(\mathrm{P}=0.223)$.

The above factors (i.e. refractive status, phone usage, age, gender, number of myopic parents, and beliefs) were incorporated into a multinomial logistic regression model and revealed that myopic refractive error status was statistically significantly associated with increasing boxcox transformed daily smartphone data usage $(\mathrm{P}=0.002)$, as well as increasing age $(\mathrm{P}=0.014)$ and number of myopic parents $(\mathrm{P}=0.008)$ (Table 2$)$. A similar multinomial logistic regression revealed that myopic refractive error status was statistically significantly associated with boxcox transformed daily time spent on mobile phone $(\mathrm{P}=0.037)$ as well as increasing age $(\mathrm{P}<0.001)$, number of myopic parents $(\mathrm{P}=0.025)$ (Table 3).

\section{DISCUSSION}

This study found an association between increased smartphone data usage and myopia with myopic participants using almost double the amount of data on a daily basis compared to those without myopia. This association remained significant even after statistical correction for possible confounders such as variation in data usage with age, number of myopic parents, sex and beliefs regarding technology that may influence smartphone usage patterns.

The lifestyle habits of today's children and teenagers have undeniably changed with advancements in technology and while the prevalence of myopia has been increasing for decades, the increased level of near visual stimulation from smartphones may pose an additional independent risk for myopia. Smartphones differ from traditional reading in various aspects such as wavelength, distance from the eye, size, contrast, resolution, temporal properties and spectral composition, all of which merit investigation. Aside from this, children and adolescents now spend more than ever using a smartphone that demands proximal attention, which may compete with other more protective activities such as time outdoors. ${ }^{6,13}$ The time (self-reported) devoted by children to smartphone 
use alone in the current study, excluding all other proximal tasks, is close to double that observed for all near work activities outside school hours in a study from Singapore (4 hours 32 minutes compared to 2 hours 42 minutes per day) ${ }^{30}$ and in a US study (4 hours 32 minutes compared to 2 hours 18 minutes). ${ }^{31}$ What's more, smartphone ownership has increased dramatically among younger age groups in both advanced and emerging economies, ${ }^{32}$ with over $99 \%$ of students in the current study owning a smartphone and younger participants spending more time on a smartphone in bed compared to older students. Our findings indicate that children and adolescents are now spending substantially more time focusing on proximal tasks compared to that observed in studies conducted in the early and pre-smartphone era. ${ }^{11,31}$

In 2001, before the advent of smartphones, Saw et al. reported myopic children spent 40 minutes more than non-myopic participants participating in total near work activities daily. ${ }^{30}$ Mutti et al. also reported myopes spent an additional 42 minutes per day on the computer, studying and reading compared to non-myopes. ${ }^{31}$ This is similar to the additional 32 minutes spent by myopes using their smartphones compared to nonmyopes reported herein. There is an apparent discordance, however, in the level of data and time usage differences observed between myopes and non-myopes. It is highly unlikely that the large data disparity is accurately reflected in the relatively small time difference found using the self-reported measure. Although statistically significant, the correlation between data usage and self-reported usage time in this study was weak, which possibly indicates low criterion validity for self-reported measures. ${ }^{33}$ There is evidence to suggest that self-reported measures of smartphone use are typically underestimated and not reliable indicators of actual use. ${ }^{34}$ Records of data usage, as collected herein, provide an objective, quantifiable and verifiable measure of phone use over an extended period of time, yielding a better indicator of smartphone behaviour than self-reported usage data. Furthermore, there is no validated questionnaire developed to assess subjective near work or smartphone usage, which is a limitation of any study that relies on self-reported data. Therefore the use of smartphone data as a surrogate indicator of phone use provides a better indicator of smartphone behaviour than self-reported usage data. ${ }^{29}$ The extended period of data usage evaluated is particularly important in that it limits the possible influence of theoretical confounders 
such as time of week (weekday versus weekend). Additionally the data is likely more reflective of typical daily life and not limited to short term recall which would influence self-reported time usage estimates.

Although sex-based differences in myopia prevalence in children have been identified in certain populations, ${ }^{35}$ sex was not statistically significantly associated with myopia status in this study, which is in agreement with observations in the Northern Ireland Childhood Errors of Refraction (NICER) study in Northern Ireland.[4] Perceptions relating to the possible ocular effects of smartphones were also explored as a means to elucidate the impact, if any, of such beliefs on the habitual usage of such devices. Our findings suggest that believing phone usage is deleterious to eye health does not limit use. This belief was expressed more often among myopes, in whom smartphone use was greatest.

A range of factors could be associated with the onset and/or progression of myopia in smartphone use which merit further investigation. These include excessive accommodation or closer working demands, ${ }^{10,31,36}$ higher AC/A ratios, ${ }^{37,38}$ and peripheral defocus. ${ }^{5,39,40}$ Furthermore, bedtime mobile phone use can disturb and delay sleep, ${ }^{41-43}$ and future research should continue to investigate associations between myopia and circadian rhythm, lack of sleep and poor sleep quality. 8,9,44

\section{Limitations of the study}

The results of this study are limited in that the case control design limits any causal inferences regarding the observed association between smartphone use and myopia. Future studies should seek to address causality through prospective design. The study, however, represents a large study sample of smartphone users across the entire education level and age spectrum during which myopia development and progression is most likely, ${ }^{45}$ and thus, the period during which environmental influences may pose a significant risk to the development of myopic refractive error. 
One consideration is how much of the data usage relates to visual tasks. This study predates iOS 12's built-in "screen time" app that provides daily and weekly activity reports of the total time a person spends in each app they use. ${ }^{46}$ Background programs as well as some apps (e.g. apps which download files and videos or high resolution video streaming apps such as YouTube and Netflix) use more data so smartphone data consumption does not necessarily correlate with time spent looking at a smartphone, ${ }^{47}$ however it is likely that any influence of such factors is balanced across the two study groups. It has also been demonstrated that the use of social networking apps account for the majority of active time spent on a smartphone and corresponding data traffic. ${ }^{48}$ Interaction with these social media apps requires a high level of visual participation. Additionally, applications that play music and therefore do not require a person to look at a screen were not in the top applications that used most data in this study.

As the study was performed in a classroom rather than a clinical setting, a formal eye examination was not conducted as part of the study. However, a qualified optometrist carefully reviewed every participant that reported spectacle/contact lens use in order to determine their refractive status. This method is more robust than self-classification of myopia status which has been performed in a range of studies. Self-classification of myopia has been found to be reasonably reliable and provides lower bound to any potential underestimation. ${ }^{49}$ The possibility that some children may have had uncorrected refractive error may have led to an underestimation of the number of myopes. As a validation, the proportion of myopes in this study attending primary (<13years) and secondary school (13-18 years) was 15\% and 26\% respectively; comparable to the prevalence of myopia in schoolchildren reported in the recent Ireland Eye Study (12-13 years 19.9\%) and to the UK NICER study (12-13 years 16.4\%, 18-20 years $18.6 \%$ ), so any underestimation is likely minimal. ${ }^{3}$ The confirmation of the association between myopic parents and myopia in their children also affirms the validity of the myopic classification procedure.

Time spent outdoors was not recorded in the study and extensive screen time may influence time spent participating in outdoor activities, although mobile phone use is not limited to indoors or outdoors. Although we cannot be definitive as to whether more 
smartphone usage equates to less time outdoors, it is highly likely that the levels of daily usage reported herein would certainly compete with and limit the time available to children and adolescents for outdoors based activities. Future studies should incorporate objective measures of light and outdoors exposure patterns to address this issue more comprehensively. ${ }^{50}$

\section{CONCLUSION}

The escalating prevalence of myopia is not a recent phenomenon and certainly pre-dates smartphones, but the current generation of children are the first to grow up in an era of smartphone dependency. This study demonstrates an association between myopia and smartphone data usage. Children are now spending substantially more time focusing on proximal tasks compared to that observed in studies conducted in the pre-smartphone era, posing an additional environmental risk factor for myopia. Given the serious nature of the ocular health risks associated with myopia, our findings indicate that this relationship merits more detailed investigation. 


\section{REFERENCES}

1. Holden BA, Fricke TR, Wilson DA, et al. Global Prevalence of Myopia and High Myopia and Temporal Trends from 2000 through 2050. Ophthalmology 2016; 123: 1036-1042.

2. Modjtahedi BS, Ferris FL, Hunter DG, et al. Public Health Burden and Potential Interventions for Myopia. Ophthalmology 2018; 125(5): 628-630.

3. McCullough SJ, O’Donoghue L, Saunders KJ. Six Year Refractive Change among White Children and Young Adults: Evidence for Significant Increase in Myopia among White UK Children. PLoS One 2016; 11: e0146332.

4. Mäntyjärvi MI. Changes of refraction in schoolchildren. Arch Ophthalmol 1985; 103: 790-2.

5. Flitcroft DI. The complex interactions of retinal, optical and environmental factors in myopia aetiology. Prog Retin Eye Res 2012; 31: 622-60.

6. French AN, Ashby RS, Morgan IG, et al. Time outdoors and the prevention of myopia. Exp Eye Res 2013; 114: 58-68.

7. Morgan IG, French AN, Ashby RS, et al. The epidemics of myopia: Aetiology and prevention. Prog Retin Eye Res 2018; 62: 134-149.

8. Ayaki M, Torii H, Tsubota K, et al. Decreased sleep quality in high myopia children. Sci Rep 2016; 6: 1-9.

9. Chakraborty R, Ostrin LA, Nickla DL, et al. Circadian rhythms, refractive development, and myopia. Ophthalmic Physiol Opt 2018; 38: 217-245.

10. Mountjoy E, Davies NM, Plotnikov D, et al. Education and myopia: assessing the direction of causality by mendelian randomisation. BMJ 2018; 361: k2022.

11. Saw S-M, Zhang M-Z, Hong R-Z, et al. Near-work activity, night-lights, and myopia in the Singapore-China study. Arch Ophthalmol 2002; 120: 620-7.

12. Dirani M, Crowston JG, Wong TY. From reading books to increased smart device screen time. Br J Ophthalmol 2019; 103: 1-2.

13. Escobar-Chaves SL, Anderson CA. Media and risky behaviors. Futur Child 2008; 18: 147-80.

14. Terras MM, Ramsay J. Family Digital Literacy Practices and Children's Mobile Phone Use. Front Psychol 2016; 7: 1957. 
15. Anderson M, Jiang J. Teens, Social Media and Technology 2018, www.pewresearch.org. (2018, accessed 24 August 2018).

16. O' Neill B, Dinh T, Mcdonnell D, et al. Net Children Go Mobile. Initial findings from Ireland, http://www.dit.ie/cser/media/ditcser/digitalchildhoods/NCGM_Ireland_initialfind ingsreport_complete.pdf (2014, accessed 26 February 2018).

17. Ofcom. Children and Parents: Media Use and Attitudes Report, https://www.ofcom.org.uk/_data/assets/pdf_file/0020/108182/children-parentsmedia-use-attitudes-2017.pdf (2017, accessed 10 January 2019).

18. Fernández-Montero A, Olmo-Jimenez JM, Olmo N, et al. The impact of computer use in myopia progression: A cohort study in Spain. Prev Med (Baltim) 2015; 71: 67-71.

19. Damian C, Artur M, Maria U, et al. Reading, writing, working on a computer or watching television, and myopia. Klin Oczna 2010; 112: 293-5.

20. Zhou J, Ma Y, Ma J, et al. Prevalence of myopia and influencing factors among primary and middle school students in 6 provinces of China. Zhonghua Liu Xing Bing Xue Za Zhi 2016; 37: 29-34.

21. Ku P-W, Steptoe A, Lai Y-J, et al. The Associations between Near Visual Activity and Incident Myopia in Children: A Nationwide 4-Year Follow-up Study. Ophthalmology 2019; 126: 214-220.

22. Saxena R, Vashist P, Tandon R, et al. Prevalence of myopia and its risk factors in urban school children in Delhi: the North India Myopia Study (NIM Study). PLoS One 2015; 10: e0117349.

23. Enthoven CA, Tideman JWL, Roelof J, et al. The impact of computer use on myopia development in childhood: The Generation R study. Prev Med (Baltim) 2020; $132: 105988$.

24. Long J, Cheung R, Duong S, et al. Viewing distance and eyestrain symptoms with prolonged viewing of smartphones. Clin Exp Optom 2017; 100: 133-137.

25. Guan H, Yu NN, Wang H, et al. Impact of various types of near work and time spent outdoors at different times of day on visual acuity and refractive error among Chinese school-going children. PLoS One 2019; 14: e0215827.

26. Liu S, Ye S, Xi W, et al. Electronic devices and myopic refraction among 
children aged 6-14 years in urban areas of Tianjin, China. Ophthalmic Physiol Opt 2019; 39: 282-293.

27. Lanca C, Saw SM. The association between digital screen time and myopia: A systematic review. Ophthalmic Physiol Opt 2020; [Epub ahead of print].

28. Yang G-Y, Huang L-H, Schmid KL, et al. Associations Between Screen Exposure in Early Life and Myopia amongst Chinese Preschoolers. Int J Environ Res Public Health 2020; 17: 1056.

29. Ellis DA, Davidson BI, Shaw H, et al. Do smartphone usage scales predict behavior? Int J Hum Comput Stud 2019; 130: 86-92.

30. Saw S, Chua W, Hong C, et al. Nearwork in Early-Onset Myopia. Invest Ophthalmol Vis Sci 2002; 43: 332-339.

31. Mutti DO, Mitchell GL, Moeschberger ML, et al. Parental Myopia, Near Work, School Achievement, and Children's Refractive Error. Investig Opthalmology Vis Sci 2002; 43: 3633-3640.

32. Pew Research Centre. Global Attitudes and Trends. Smartphone Ownership Is Growing Rapidly Around the World, but Not Always Equally | Pew Research Center, https://www.pewresearch.org/global/2019/02/05/smartphone-ownershipis-growing-rapidly-around-the-world-but-not-always-equally/ (2019, accessed 28 January 2020).

33. Boase J, Ling R. Measuring Mobile Phone Use: Self-Report Versus Log Data. $J$ Comput Commun 2013; 18: 508-519.

34. Lee H, Ahn H, Nguyen TG, et al. Comparing the Self-Report and Measured Smartphone Usage of College Students: A Pilot Study. Psychiatry Investig 2017; 14: 198.

35. Rudnicka AR, Kapetanakis V V, Wathern AK, et al. Global variations and time trends in the prevalence of childhood myopia, a systematic review and quantitative meta-analysis: implications for aetiology and early prevention. $\mathrm{Br} J$ Ophthalmol 2016; 100: 882-890.

36. Huang H-M, Chang DS-T, Wu P-C, et al. The Association between Near Work Activities and Myopia in Children?A Systematic Review and Meta-Analysis. PLoS One 2015; 10: e0140419.

37. Gwiazda J, Grice K, Thorn F. Response AC/A ratios are elevated in myopic 
children. Ophthalmic Physiol Opt 1999; 19: 173-9.

38. Zadnik K, Sinnott LT, Cotter SA, et al. Prediction of Juvenile-Onset Myopia. JAMA Ophthalmol 2015; 133: 683.

39. Smith EL, Hung L-F, Huang J, et al. Relative peripheral hyperopic defocus alters central refractive development in infant monkeys. Vision Res 2009; 49: 2386-92.

40. Mutti DO, Hayes JR, Mitchell GL, et al. Refractive error, axial length, and relative peripheral refractive error before and after the onset of myopia. Investig Ophthalmol Vis Sci 2007; 48: 2510-19.

41. Fowler J, Noyes J. A study of the health implications of mobile phone use in 814s 1. DYNA 2017; 84: 228-233.

42. Bartel K, Scheeren R, Gradisar M. Altering Adolescents' Pre-Bedtime Phone Use to Achieve Better Sleep Health. Health Commun 2018; 34: 456-462.

43. Stiglic N, Viner RM. Effects of screentime on the health and well-being of children and adolescents: a systematic review of reviews. BMJ Open 2019; 9: e023191.

44. Gifford KL, Richdale K, Kang P, et al. IMI - Clinical management guidelines report. Investig Ophthalmol Vis Sci 2019; 60: M184-M203.

45. Pärssinen O, Kauppinen M, Viljanen A. The progression of myopia from its onset at age 8-12 to adulthood and the influence of heredity and external factors on myopic progression. A 23-year follow-up study. Acta Ophthalmol 2014; 92: 730-739.

46. Apple Inc. iOS 12 introduces new features to reduce interruptions and manage Screen Time, https://www.apple.com/ie/newsroom/2018/06/ios-12-introducesnew-features-to-reduce-interruptions-and-manage-screen-time/ (accessed 15 May 2019).

47. Sani AA, Tan $\mathrm{Z}$, Washington $\mathrm{P}$, et al. The wireless data drain of users, apps, \&amp; platforms. ACM SIGMOBILE Mob Comput Commun Rev 2013; 17: 1528.

48. Arsal K, Sinibaldi G, Scott M. Consumer smartphone analytics : applications and services. Research Survey Report. 2017.

49. Cumberland PM, Chianca A, Rahi JS. Accuracy and Utility of Self-report of Refractive Error. JAMA Ophthalmol 2016; 134: 794. 
50. Wolffsohn JS, Kollbaum PS, Berntsen DA, et al. IMI - Clinical Myopia Control Trials and Instrumentation Report. Investig Opthalmology Vis Sci 2019; 60: M132-M160.

\section{Corresponding author: Saoirse McCrann}

e-mail address: saoirse.mccrann@tudublin.ie 


\section{Table 1: Participant demographics, smartphone behaviour and related beliefs}

according to refractive status. Note: Results indicated as mean \pm standard deviation (range).

$\mathrm{P}$ values calculated using the Mann-Whitney U test or, where otherwise indicated, using ChiSquare $(\dagger)$ and Kruskal-Wallis H (†) tests.

\begin{tabular}{|c|c|c|c|}
\hline & Myopes & Non-Myopes & P Value \\
\hline \multicolumn{4}{|l|}{ Demographics } \\
\hline Age (mean) & $18 \pm 4(9,33)$ & $16 \pm 5(10,40)$ & 0.002 \\
\hline Male & $38 \%(48 / 128)$ & $48 \%(124 / 257)$ & $0.058 \dagger$ \\
\hline \multicolumn{4}{|l|}{ Proportion of myopic parents } \\
\hline No Myopic Parents & $40 \%(55 / 137)$ & $56 \%(143 / 257)$ & $0.11 t$ \\
\hline One Myopic Parent & $45 \%(61 / 137)$ & $36 \%(92 / 257)$ & \\
\hline Two Myopic Parents & $15 \%(21 / 137)$ & $9 \%(24 / 257)$ & \\
\hline \multicolumn{4}{|l|}{ Smartphone Behaviour } \\
\hline Data Usage per day (MB) & $1131 \pm 1748(0.36,10534)$ & $614 \pm 902(0,6000)$ & 0.001 \\
\hline Time on Phone per day (minutes)* & $288 \pm 174(10,1080)$ & $258 \pm 163(5,785)$ & 0.09 \\
\hline Phone in Bed every night & $64 \%(86 / 134)$ & $61 \%(159 / 259)$ & $0.72 \ddagger$ \\
\hline Usage time in bed (minutes) & $67 \pm 68(0,455)$ & $71 \pm 104(1,1335)$ & 0.65 \\
\hline
\end{tabular}

\section{Smartphone Related Beliefs}

Belief screens may affect eyes

$84 \%(112 / 134)$

$68 \%(175 / 259)$

0.001

Belief screens may cause myopia $\quad 31 \%(19 / 127)$

$25 \%(61 / 246)$

0.223 
Table 2: Summary of logistic regression analysis for variables predicting myopic status by boxcox of daily data usage (MB), age, parental myopia, a belief that technology can negatively impact eyes and sex for $n=286$.

\begin{tabular}{|c|c|c|c|c|c|c|}
\hline Independent Variable & B & SE(B) & z-Value & Prob & Odds & $\begin{array}{l}\text { Odds } \\
\text { Confidence } \\
\text { Intervals }\end{array}$ \\
\hline Boxcox Daily Data Usage & 0.08068 & 0.02583 & 3.123 & 0.002 & 1.08 & $(1.031,1.142)$ \\
\hline Age & 0.08708 & 0.03541 & 2.460 & 0.014 & 1.09 & $(1.02,1.17)$ \\
\hline Number of Myopic Parents & 0.44240 & 0.19709 & 2.245 & 0.008 & 1.55 & $(1.06,2.301)$ \\
\hline Technology Beliefs $\uparrow$ & 0.4448 & 0.31001 & 1.434 & 0.151 & 1.55 & $(1.001,3.301)$ \\
\hline Sex & 0.10949 & 0.28154 & 0.389 & 0.697 & 1.12 & $(0.644,1.94)$ \\
\hline
\end{tabular}


Table 3: Summary of logistic regression analysis for variables predicting myopic status by boxcox of daily time spent on a smartphone(mins), age, parental myopia, a belief that technology can negatively impact eyes and sex for $n=364$.

\begin{tabular}{|c|c|c|c|c|c|c|}
\hline Independent Variable & B & SE(B) & z-Value & Prob & Odds & $\begin{array}{l}\text { Odds } \\
\text { Confidence } \\
\text { Intervals }\end{array}$ \\
\hline Boxcox Daily Time Usage & 0.02585 & 0.01241 & 2.084 & 0.0372 & 1.026 & $(1.001,1.051)$ \\
\hline Age & 0.13115 & 0.03069 & 4.273 & $<0.001$ & 1.14 & $(1.076,1.21)$ \\
\hline Number of Myopic Parents & 0.39767 & 0.17823 & 2.231 & 0.025 & 1.488 & $(1.05,2.116)$ \\
\hline Technology Beliefs $\dagger$ & 0.53595 & 0.29441 & 1.820 & 0.0687 & 1.709 & $(0.97,3.092)$ \\
\hline Sex & -0.4620 & 9.25381 & -0.182 & 0.856 & 0.954 & $(0.579,1.57)$ \\
\hline
\end{tabular}


Figure 1: Participant recruitment, data capture and refractive status confirmation flowchart

Figure 2: Myopic and non-myopic participants' daily smartphone data usage (MB) and daily self-reported smartphone usage time (minutes) according to education level. A significant difference was found in daily data usage between myopic and non-myopic university students $(\mathrm{P}=0.018$, Mann-Whitney $\mathrm{U}$ test $)$ and in daily time on phone between myopic and non-myopic primary school students $(\mathrm{P}=0.015$, Mann-Whitney $\mathrm{U}$ test $)$. 
Figure 1: Participant recruitment, data capture and refractive status confirmationflowchart $159 \times 229 \mathrm{~mm}(600 \times 600 \mathrm{DPI})$

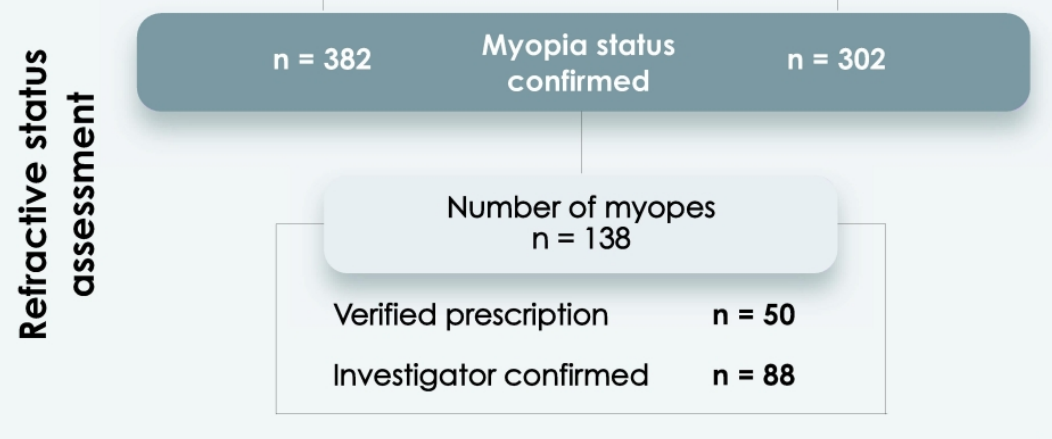

Completed consent + returned questionnaire $n=402$

$\frac{1}{2}$
$\frac{7}{2}$
$\frac{0}{0}$
응
음

\section{Provided smartphone} stimate $n=396$

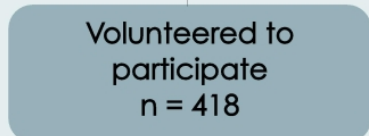
rovided smartphone output $n=321$ 
A) Daily Data Usage

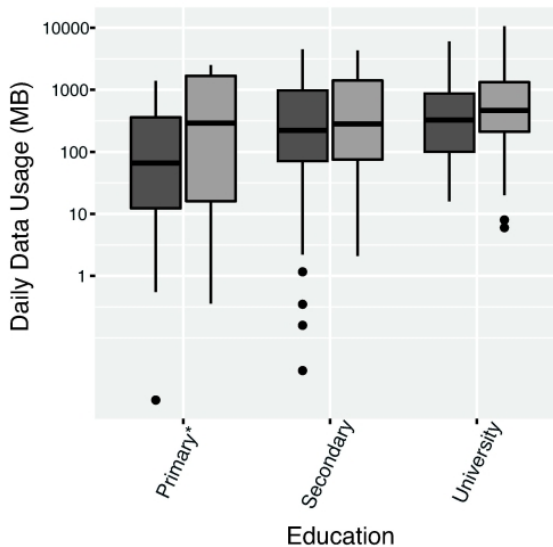

B) Daily Time Spent on Phone (self-report)

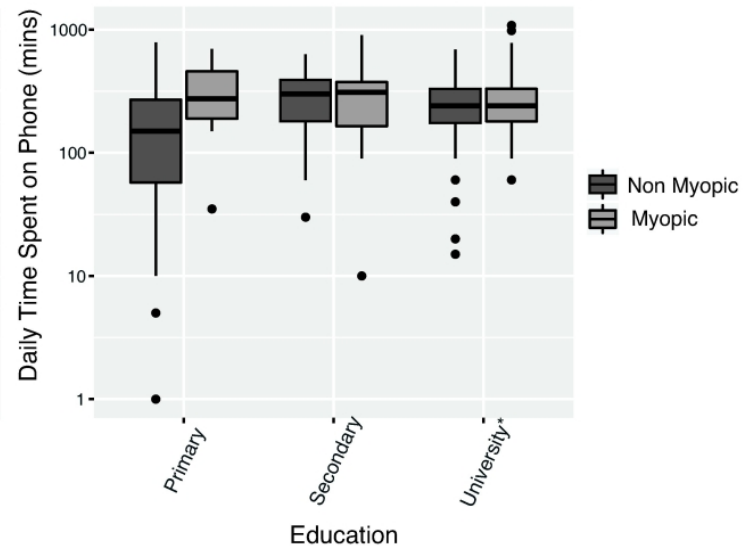

Myopic and non-myopic participants' daily smartphone data usage (MB) and daily self-reported smartphone usage time (minutes) according to education level. A significant difference was found in daily data usage between myopic and non-myopic university students $(P=0.018$, Mann-Whitney $U$ test) and in daily time on phone between myopic and non-myopic primary school students ( $P=0.015$, Mann-Whitney $U$ test).

$$
196 \times 90 \mathrm{~mm}(600 \times 600 \text { DPI })
$$




\section{Questionnaire for over 16 year olds}

(This questionnaire is anonymous)

Today's Date

\section{Mobile Data Usage}

Android Users (Samsung/ Huawei/HTC/Sony) (if you have an iPhone use page 2)

1. Click on Apps and then click on the Settings icon

2. Click on the search box on the top right corner

3. Type "data usage"

4. Click on DATA USAGE (under connections)

5. Look under the heading MOBILE

What is your MOBILE DATA USAGE? (eg.2GB)

(make sure to write if it is GB or MB)

What is the PERIOD FOR DATA USAGE (written directly beside) (eg. 1-30 Sep)

6. Click on mobile data usage

What are the top 3 apps named?

1.

2.

3.

7. Now go back to the previous screen and scroll down to WI-FI What is your WI-FI data usage? (make sure to write if it is GB or MB)

What is the PERIOD FOR WIFI USAGE (eg. 18 Dec 2017-2 Jan 2018) 


\section{iPhone Users}

1. Click on the Settings icon

2. Click on mobile data

3. Look at the current period (under the heading mobile data)

DATA USAGE IN CURRENT PERIOD (eg.50GB)

(make sure to write if it is GB or MB) (NOT CURRENT PERIOD

ROAMING, JUST CURRENT PERIOD)

4. Scroll down to see a list of apps and the amount of mobile data that each app used

TOP 3 APPS THAT USE THE MOST DATA (watch out! this is not in order on your phone, so look for the biggest. GB is bigger than $\mathrm{MB}$ )

1.

\section{2.}

\section{3.}

3. Scroll down to Wi-Fi Assist

What is your WI-FI data usage?

(make sure to write if it is $\mathrm{GB}$ or $\mathrm{MB}$ )

4. Scroll to the very bottom and check when last reset was

LAST RESET (scroll to very bottom of page)

$\overline{\text { Day }} \overline{\text { Month }} \overline{\text { Year }}$ 


\section{Questionnaire}

1. What age are you?

2. Are you

Male

Female

3. Are you shortsighted? (please ask the Optometrist in your classroom to confirm this)
Yes
No
(If no skip to question 6)

4. Please show your glasses/contact lens prescription to the Optometrist in your classroom

RE (OD)

LE (OS)

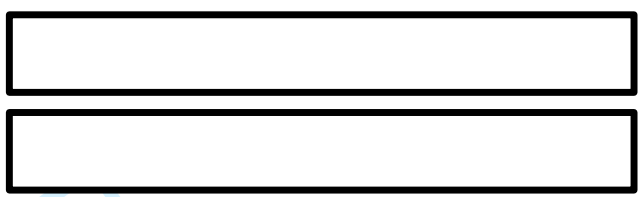

5. What age did you first get glasses?

6. Are any of your parents short-sighted?

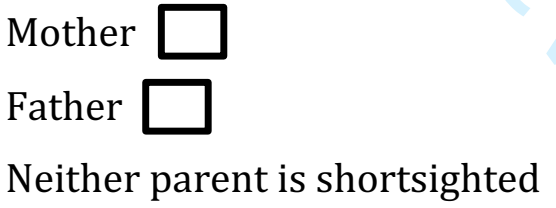

7. How much time do you spend per day on your phone

hours and minutes

8. What is the longest length of time you spend on a phone at any one period in a week (e.g. 2 hours watching a movie) hours and minutes

9. Do you watch TV programs/films on your phone or iPad? Never Sometimes (once a week or less) Often (more than twice a week)<smiles>C1=CCCC1</smiles>

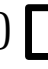


10. Do you use your phone/kindle/tablet to read a book? ${ }^{C}$ tinical and Experimetry

Never $\square$

Occasionally (once a month or less) $\square$

Regularly (on a weekly basis) $\square$

Frequently (almost daily)

11. What are you doing usually when looking at your phone screen (number from 1 to 5,1 being the most used and 5 being the least used)

Email/on the internet $\square$

Social media

Non-social media apps/games

Watching Video

Texting/WhatsApp

12. How often do you look at your phone after you've gone to bed?

Never $\square$

Sometimes ( 1 or 2 nights per week) $\square$

Most nights

For how long? hours mins

13. Do you think the use of technology (laptop/phone/iPad/tablet) has an impact on your eyes?

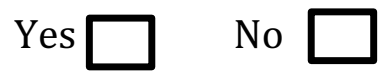

14. If you answered yes to question 12, what do you think are the potential risks/effects on the eyes from using screens like a laptop or phone? 